\title{
PENGATURAN JAM KEDATANGAN TRUK DENGAN MENGGUNAKAN SHIPPING OPERATION DIAGRAM DI PT XYZ
}

\author{
Hendrastuti Hendro 1), Irma Agustiningsih Imdam ${ }^{2)}$, Justi Anjarsari ${ }^{3)}$ \\ 1), 2), 3) Teknik Industri Otomotif, Politeknik STMI Jakarta, Jl. Letjen. Suprapto no. 26, Cempaka \\ Putih, Jakarta Pusat, 10510 \\ E-mail: hendras.agung@gmail.com
}

\begin{abstract}
$P T X Y Z$ as an automotive components manufacturer that does the production process based on orders from customers, the timeliness of product delivery and the quality of the product is important. The main problem faced by PT XYZ is late delivery of product. The next problem is resulting in the accumulation of finished products in the storage area and delivery schedules have not been arranged properly. The objectives of the study were to determine the arrival patterns of the trucks arriving at the same time, calculate the pulling time on the delivery delay, and determine the information tool for the delivery schedule to be delivered properly. Expected result of research is to create the delivery schedules number and set the arrival time of the truck by using shipping operation diagram in order to avoid delays in product delivery and no buildup of finished products in the storage area.
\end{abstract}

Keywords: Automotive components, late delivery, delivery schedules, arrival time, shipping operation diagram.

\begin{abstract}
ABSTRAK
PT XYZ merupakan sebuah perusahaan yang bergerak dibidang komponen otomotif melakukan proses produksi berdasarkan pesanan dari pelanggan, maka ketepatan waktu pengiriman produk dan kualitas produk yang dihasilkan sangatlah penting. Permasalahan utama PT XYZ adalah adanya keterlambatan pengiriman produk. Permasalahan selanjutnya adalah adanya penumpukan produk jadi di area penyimpanan, serta jadwal pengiriman belum tersusun dengan baik. Tujuan penelitian adalah menentukan pola kedatangan truk yang tiba pada waktu yang sama, menghitung waktu pulling pada keterlambatan pengiriman, dan menentukan alat informasi agar jadwal pengiriman dapat tersampaikan dengan baik. Hasil penelitian yang diharapkan adalah mengatur jam kedatangan truk dengan menggunakan shipping operation diagram agar tidak terjadi keterlambatan pengiriman barang dan tidak ada penumpukan barang jadi di area penyimpanan.
\end{abstract}

Kata Kunci: Komponen otomotif, keterlambatan pengiriman, jadwal pengiriman , waktu kedatangan, shipping operation diagram

\section{PENDAHULUAN}

Pengiriman sangat penting untuk menjaga kepercayaan serta kepuasan pelanggan dalam memberikan pelayanan yang prima. PT XYZ merupakan sebuah perusahaan yang bergerak dibidang komponen otomotif yang menghasilkan rear axle, propeller shaft, dan transmisi. PT XYZ melakukan proses produksi berdasarkan pesanan dari pelanggan, maka ketepatan waktu pengiriman produk dan kualitas produk yang dihasilkan sangatlah penting..Kunci keberhasilan dari perusahaan pengiriman barang adalah bagaimana mengfisienkan bisnis untuk mencapai standar pelayanan prima dengan biaya rendah (Lam, J.S.L., et al., 2018). Pengiriman memiliki indikator kunci untuk mengukur kecepatan, akurasi, volume dan kondisi lainnya. Hambatan-hambatan yang dapat terjadi pada proses pengiriman antara lain keterlambatan pengeluaran barang, kekurangan barang, urutan rencana delivery tidak tepat, armada angkutan tidak memadai, dan truk tidak sesuai standar (Hutapea, 2017). PT XYZ mengalami kendala dalam hal pengiriman barang. Hal ini mengakibatkan keterlambatan dalam pengiriman barang sampai ke konsumen sehingga terjadi 
penumpukan barang di area penyimpanan. Gudang adalah tempat penyimpanan sementara dan pengambilan persediaan untuk mendukung kegiatan operasi bagi operasi berikutnya, ke lokasi distribusi atau kepada konsumen akhir (Martono, 2015).

Pada PT XYZ pola kedatangan truk di area shipping belum optimal sehingga pengirimannya tidak sesuai dengan waktu yang ditentukan. Tujuan dari penelitian ini adalah membuat pola kedatangan (loading pattern) truk di area shipping dengan mengatur ulang waktu kedatangan dan keberangkatan truk dengan rentang waktu \pm 15 menit. Metode yang digunakan adalah Shipping Operation Diagram (SOD) dan cycle issue kanban. Faktor-faktor yang berpengaruh dalam menentukan cycle issue kanban adalah jarak pemasok, karakteristik dan varian komponen yang dipasok, jumlah pesanan per hari, dan kapasitas truk (Monden, 2000)

\section{METODE PENELITIAN}

Pada penelitian ini, data yang digunakan adalah data waktu keberangkatan truk untuk masingmasing konsumen selama 30 hari di area pengiriman. Pengamatan dilakukan terhadap 3 konsumen yaitu HMMI, IAMI, dan KTB. Setiap truk yang datang untuk mengisi palet kosong akan diisi dengan sejumlah barang sesuai permintaan pelanggan. Perusahaan menetapkan bahwa setiap truk yang datang akan melalui beberapa tahapan. Tahapan ini diawali dengan truk datang ke PT XYZ, menuju loading dock, mengisi muatan, dan terakhir keberangkatan truk. data tersebut dicari waktu yang sering muncul untuk digunakan sebagai standar waktu dalam mengatur urutan pengiriman. Waktu kedatangan serta keberangkatan truk dalam bentuk diagram dengan menggunakan metode SOD akan ditampilkan.

Langkah awal dalam membuat SOD adalah mengumpulkan data berupa jam kerja per hari, waktu istirahat, dan total waktu yang digunakan per hari, nama pelanggan, Cycle Issue (CI), urutan pekerjaan serta waktu setiap urutan pekerjaan. Selanjutnya mengatur waktu urutan pekerjaan yang menggunakan forklift agar tidak terjadi penumpukan pekerjaan. SOD membantu operator forklift dalam mengerjakan pekerjaan sesuai urutan pekerjaan sehingga aktivitas forklift menjadi lancar. Urutan pekerjaan yang ditampilkan pada SOD adalah informasi kedatangan truk, waktu yang dibutuhkan untuk mengurus administrasi, pengisian barang di PDC, waktu yang diperlukan dalam pengecekan kualitas, loading dan unloading time serta waktu keberangkatan truk. Informasi waktu yang tertera dalam SOD adalah hasil pemetaan dari pengorganisasian waktu pengisian barang di PDC yang ditunjang dari keadaan aktual di area pengiriman.

Langkah eelanjutnya membuat pola keberangkatan truk hingga menghitung rata-rata permintaan konsumen terbesar per bulan dan per hari. Pola keberangkatan truk yang dibuat sebagai dasar pengaturan pola kedatangan (loading pattern). Pada pengaturan loading pattern, jam keberangkatan truk diatur \pm 15 menit sebelumnya atau sesudahnya, sehingga truk tidak mengalami keterlambatan akibat waktu menunggu. Langkah selanjutnya adalah membuat pulling time dengan mengatur waktu kedatangan truk dari perhitungan mundur waktu keberangkatan truk. Pulling time dilakukan guna mencari tahu kapan forklift dapat memulai dan menghentikan pulling ataupun melakukan loading ke truk pengiriman. SOD merupakan alat pengecekan untuk mengetahui apakah masih terdapat benturan waktu untuk masing-masing truk dalam pulling maupun loading karena forklift yang digunakan hanya satu untuk mengerjakan kegiatan pulling dan loading.

\section{HASIL DAN PEMBAHASAN}

Cycle issue yang digunakan sebagai acuan untuk mengatur pola kedatangan adalah 1:19:X, artinya dalam satu hari terdapat 19 kali pengiriman dan $\mathrm{X}$ merupakan gabungan interval dari semua konsumen. Adapun data yang digunakan adalah sebagai berikut:

Tabel 1. Data hasil rata-rata jam keberangkatan truk PT XYZ

\begin{tabular}{|c|c|c|c|c|}
\hline Konsumen & Sebelum & Sesudah & Cycle & Kode Warna \\
\hline \multirow[t]{3}{*}{ HMMI RA } & $5: 00$ & 5:00 & \multirow[t]{3}{*}{3} & \\
\hline & $6: 20$ & $6: 10$ & & \\
\hline & $7: 10$ & $7: 00$ & & \\
\hline \multirow[t]{2}{*}{ HMMI PS } & $5: 30$ & $5: 30$ & \multirow[t]{2}{*}{2} & \\
\hline & $8: 55$ & $8: 45$ & & \\
\hline HMMI & $11: 05$ & 11:00 & 1 & \\
\hline MEDIUM & $10: 25$ & $10: 30$ & 1 & \\
\hline \multirow[t]{6}{*}{ KTB } & $6: 45$ & $6: 40$ & \multirow[t]{6}{*}{9} & \\
\hline & $8: 10$ & $8: 20$ & & \\
\hline & 9:00 & 9:00 & & \\
\hline & $9: 50$ & $10: 00$ & & \\
\hline & $10: 40$ & $10: 45$ & & \\
\hline & $11: 30$ & $11: 30$ & & \\
\hline
\end{tabular}




\begin{tabular}{c|c|c|c|c}
\hline & $13: 30$ & $13: 20$ & \multirow{2}{*}{} & \\
\cline { 2 - 3 } & $14: 20$ & $14: 20$ & & \\
\cline { 2 - 3 } & $15: 00$ & $15: 00$ & & \\
\hline IAMI & $5: 55$ & $5: 45$ & 3 & \\
\hline & $9: 25$ & $9: 20$ & & \\
\hline & $13: 05$ & $13: 00$ & & \\
\hline
\end{tabular}

Kemudian dibuat diagram jam kedatangan truk yang telah diatur agar tidak ada truk yang datang dalam rentang waktu yang telah di tetapkan yaitu \pm
15 menit. Pola kedatangan tersebut dapat dilihat pada Gambar 1 dan Gambar 2.

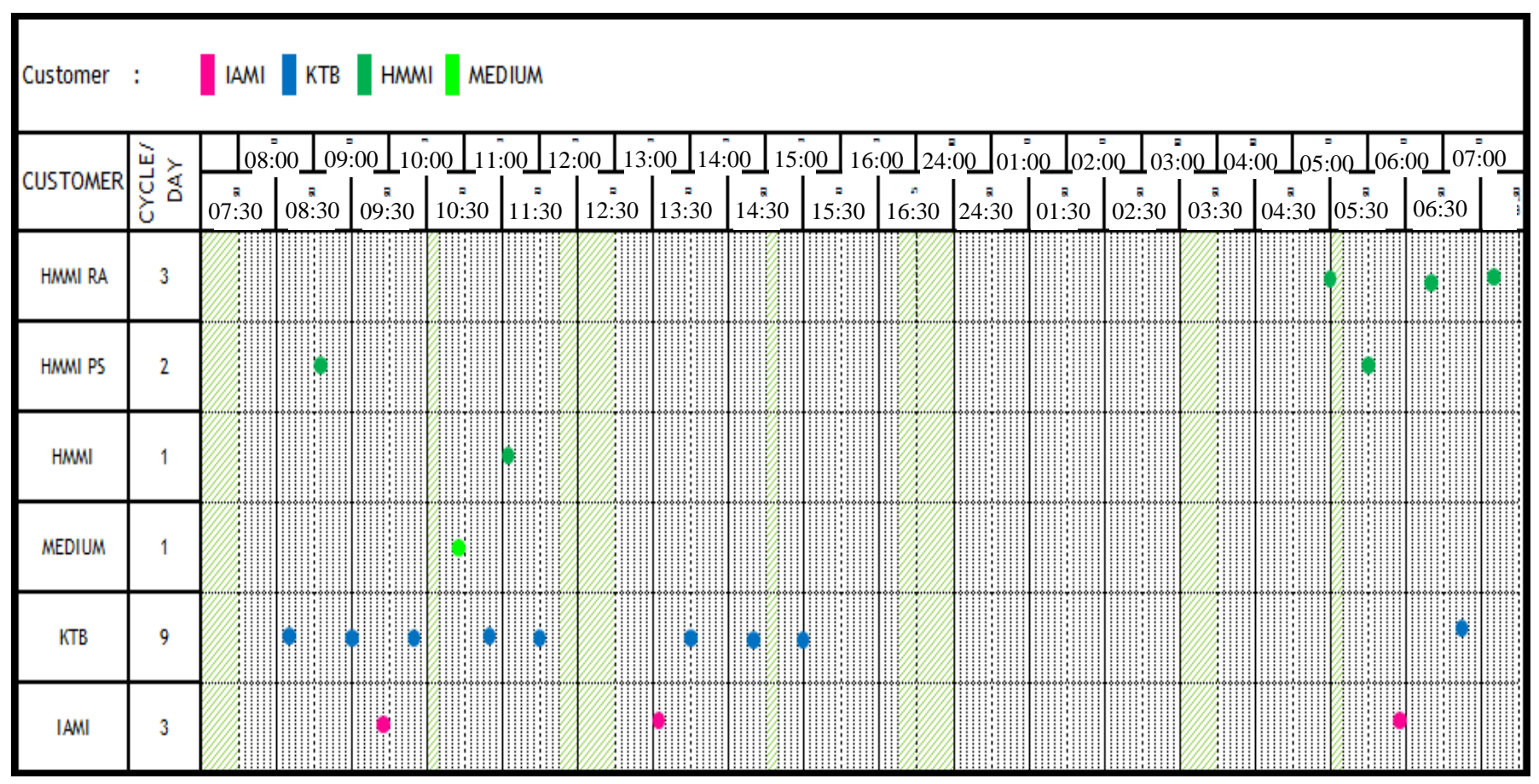

Gambar 1. Diagram Before loading pettern jam kedatangan truk

Sumber: Data Primer yang sudah diolah, 2018

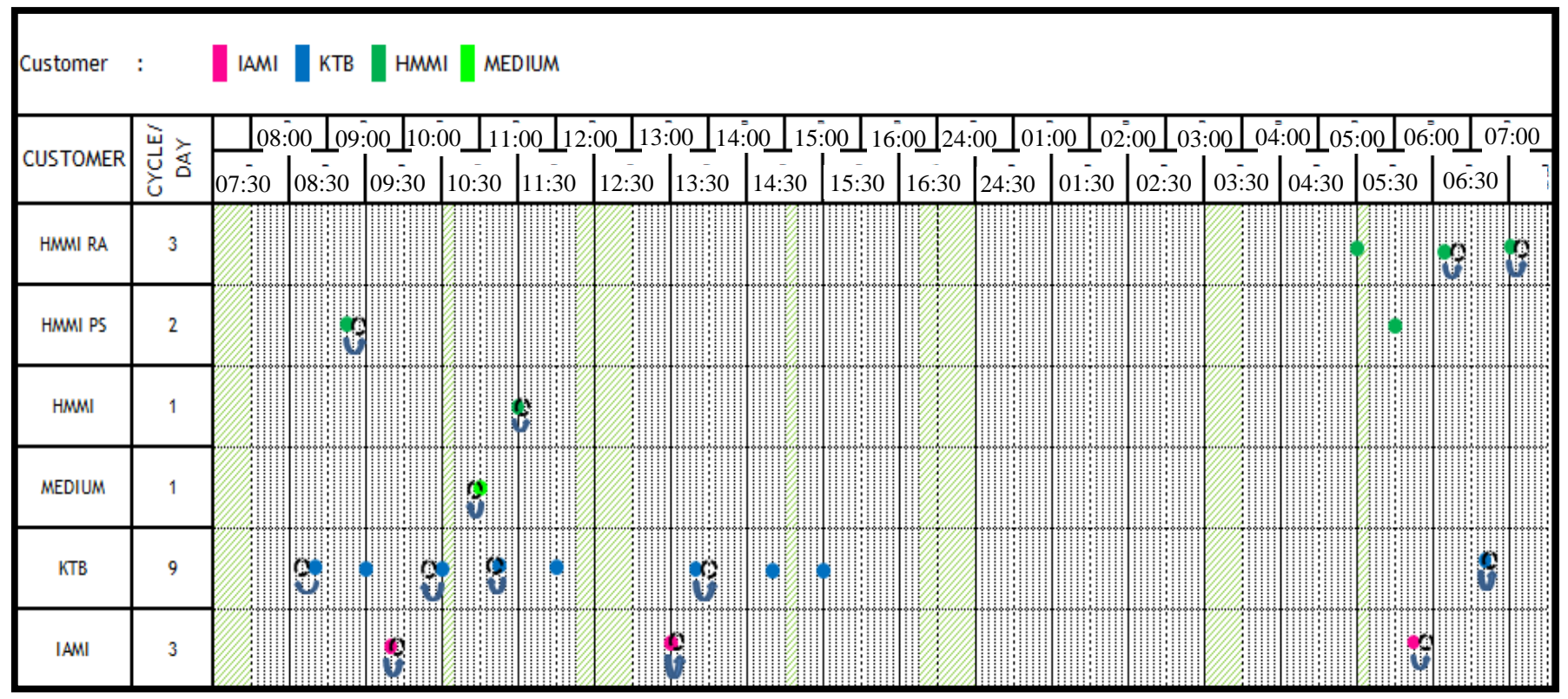

Gambar 2. Diagram After loading pettern jam kedatangan truk Sumber: Data Primer yang sudah diolah, 2018 
Loading pattern yang telah dibuat, dilakukan pengujian dengan memasukkan waktu pulling atau waktu yang digunakan forklift untuk mengisi area PDC dengan produk yang siap untuk dikirim. Pada proses pengujian ini menggunakan data Cycle time selama satu hari, jalur PDC, jam keberangkatan truk serta nama konsumen. Sedangkan informasi yang dapat kita ketahui dengan pengaturan pulling time berupa waktu mulai dan selesai pulling, waktu mulai melakukan pengisian muatan serta jeda waktu antar keberangkatan. Namun sebelumnya harus diketahui berapa lama rata-rata waktu yang dibutuhkan untuk melakukan loading-unloading dan pulling. Berdasarkan hasil perhitungan rata-rata didapat waktu yang dibutuhkan untuk loading-unloading selama 10 menit dan waktu yang dibutuhkan forklift untuk melakukan pulling selama 15 menit. Hasil pulling time yang di dapat dari tahapan diatas dapat dilihat pada Tabel 2 .
Tahapan untuk mengetahui kapan waktu memulai pulling:

1. Memasukkan jam keberangkatan truk, waktu yang dibutuhkan untuk melakukan loading dan waktu yang dibutuhkan untuk melakukan pulling.

2. Mencari waktu mulai untuk loading yaitu selisih jam keberangkatan dengan waktu loading

3. Mencari waktu selesai pulling yaitu jam mulai loading - (waktu pulling x bilangan bulat ataupun desimal yang hasilnya sama dengan waktu loading di urutan sebelumnya).

Untuk menghitung waktu selesai pulling dilakukan dari urutan terakhir terlebih dahulu.

4. Mencari waktu mulai pulling yaitu selisih jam selesai pulling dengan waktu pulling

5. Mengurut urutan sesuai jalur PDC

Tabel 2. Pulling Time

\begin{tabular}{c|c|c|c|c|c|c|c}
\hline \multirow{2}{*}{ Cycle } & PDC & \multirow{2}{*}{$\begin{array}{c}\text { Start } \\
\text { pulling }\end{array}$} & \multirow{2}{*}{$\begin{array}{c}\text { Finish } \\
\text { pulling }+\end{array}$} & \multirow{2}{*}{$\begin{array}{c}\text { Finish } \\
\text { pulling }\end{array}$} & $\begin{array}{c}\text { Start } \\
\text { loading }\end{array}$ & \multirow{2}{*}{$\begin{array}{c}\text { Finish } \\
\text { loading }\end{array}$} & \multirow{2}{*}{ Customers } \\
& AREA & $0 ; 15$ & break & & $0 ; 10$ & & \\
\hline & 1 & $3: 50$ & & $4: 05$ & $4: 50$ & $5: 00$ & HMMI RA \\
\hline 2 & 2 & $4: 05$ & & $4: 20$ & $5: 20$ & $5: 30$ & HMMI PS \\
\hline 3 & 3 & $4: 20$ & & $4: 35$ & $5: 45$ & $5: 55$ & IAMI \\
\hline 4 & 4 & $4: 35$ & & $4: 50$ & $6: 10$ & $6: 20$ & HMMI RA \\
\hline 5 & 1 & $5: 30$ & & $5: 45$ & $6: 35$ & $6: 45$ & KTB \\
\hline 6 & 2 & $5: 55$ & & $6: 10$ & $7: 00$ & $7: 10$ & HMMI RA \\
\hline 7 & 3 & $6: 20$ & & $6: 35$ & $8: 00$ & $8: 10$ & KTB \\
\hline 8 & 4 & $6: 45$ & & $7: 00$ & $8: 25$ & $8: 35$ & HMMI PS \\
\hline 9 & 1 & $7: 45$ & & $8: 00$ & $8: 50$ & $9: 00$ & KTB \\
\hline 10 & 2 & $8: 10$ & & $8: 25$ & $9: 15$ & $9: 25$ & IAMI \\
\hline 11 & 3 & $8: 35$ & & $8: 50$ & $9: 40$ & $9: 50$ & KTB \\
\hline 12 & 4 & $9: 00$ & & $9: 15$ & $10: 15$ & $10: 25$ & MEDIUM \\
\hline 13 & 1 & $9: 25$ & & $9: 40$ & $10: 30$ & $10: 40$ & KTB \\
\hline 14 & 2 & $9: 50$ & $10: 15$ & $10: 05$ & $10: 55$ & $11: 05$ & HMMI \\
\hline 15 & 3 & $10: 40$ & & $10: 55$ & $11: 20$ & $11: 30$ & KTB \\
\hline 16 & 4 & $11: 05$ & & $11: 20$ & $12: 55$ & $13: 05$ & IAMI \\
\hline 17 & 1 & $12: 40$ & & $12: 55$ & $13: 20$ & $13: 30$ & KTB \\
\hline 18 & 2 & $13: 05$ & & $13: 20$ & $14: 10$ & $14: 20$ & KTB \\
\hline 19 & 3 & $13: 55$ & & $14: 10$ & $14: 50$ & $15: 00$ & KTB \\
\hline
\end{tabular}

Sumber: Data primer yang diolah tahun 2018

Pulling time dilakukan guna mencari tahu kapan forklift dapat memulai dan menghentikan pulling ataupun melakukan loading ke truk pengiriman. SOD sebagai alat pengecekan apakah masih terdapat benturan waktu untuk masingmasing truk dalam pulling maupun loading karena forklift yang digunakan hanya satu untuk mengerjakan kegiatan pulling dan loading. SOD dimulai dari informasi kedatangan setiap konsumen lalu lanjut diproses oleh petugas PPIC selama 10 menit. Langkah selanjutnya dalam pengaturan SOD dimulai dari jam keberangkatan lalu bergerak mundur hingga pada proses pulling time. Jam keberangkatan truk diletakkan sesuai jam pada loading pattern, kemudian mundur sepuluh menit untuk melakukan loading-unloading. Setelah semua diatur mundur 10 menit dan tidak terjadi penumpukan waktu, selanjutnya mundur kembali 20 menit untuk melakukan QC check. Pada proses ini waktu $Q C$ check boleh bertabrakan dengan waktu pulling ataupun loading karena petugas forklift dengan petugas $Q C$ check berbeda. Ketika waktu 
$Q C$ check telah diatur maka selanjutnya mundur kembali dengan mengalikan waktu pulling sebesar 15 menit dan bilangan normal atau desimal disesuaikan dengan urutan PDC yang dijadikan sebagai penanda waktu pulling. Seluruh pengaturan pada urutan pekerjaan yang terdapat di SOD saling terhubung satu sama lain, yang menandakan pengiriman tidak akan berjalan bila proses sebelumnya belum selesai dikerjakan. Adapun SOD tersebut dapat dilihat pada Gambar 3.

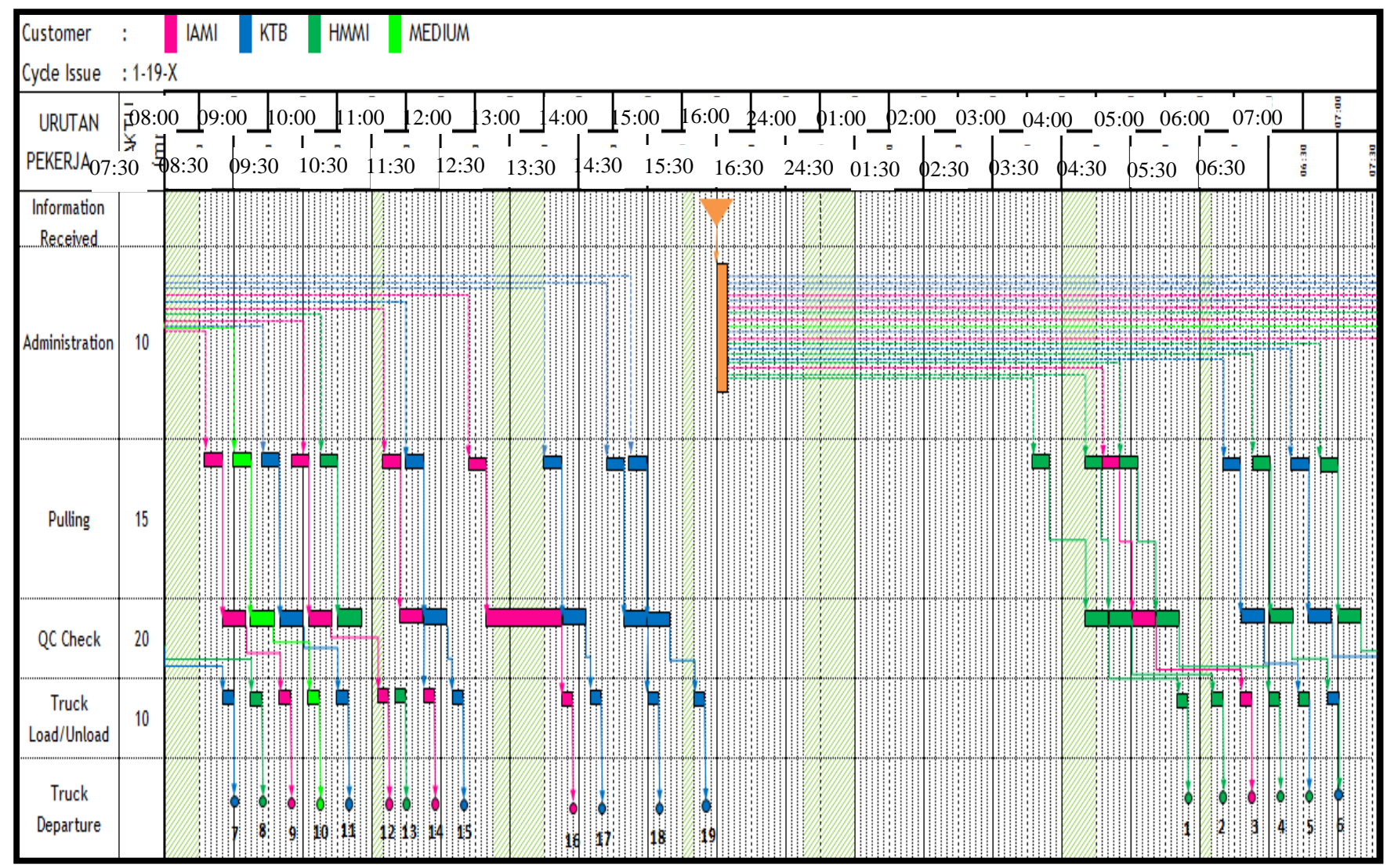

Gambar 3. Diagram Shipping Operation Diagram (SOD)

Sumber: Hasil Pengolahan data Primer dan Sekunder tahun 2018

Sistem jam kedatang truk yang telah dibuat dengan SOD dapat berjalan baik apabila didukung dengan area $P D C$. Area PDC yang sudah ada tidak dibuat urut sesuai dengan urutan pengiriman yang telah dibuat. Untuk itu perubahan area PDC perlu dilakukan dengan mempertimbangkan luas area serta jumlah barang yang masuk kedalam area FG serta jumlah permintaan barang.

Empat jalur PDC yang ada dibuat berurutan sesuai dengan kedatangan truk. Pertanyaan yang timbul dari urutan kedatangan truk dengan pengaturan jalur PDC adalah bagaimana menentukan jalur mana yang dahulu diisi dengan produk yang siap kirim dan bagaimana urutan pengirimannya? Pengaturan tag PDC lah yang dapat menjawab pertanyaan tersebut. Informasi yang diberikan oleh tag PDC memudahkan petugas forklift, driver, dan petugas delivery untuk mengetahui jalur mana yang siap kirim dan jalur mana yang harus di isi. Perubahan tat lertak pada area PDC yang dapat dilihat pada Gambar 4 dan 5 . 


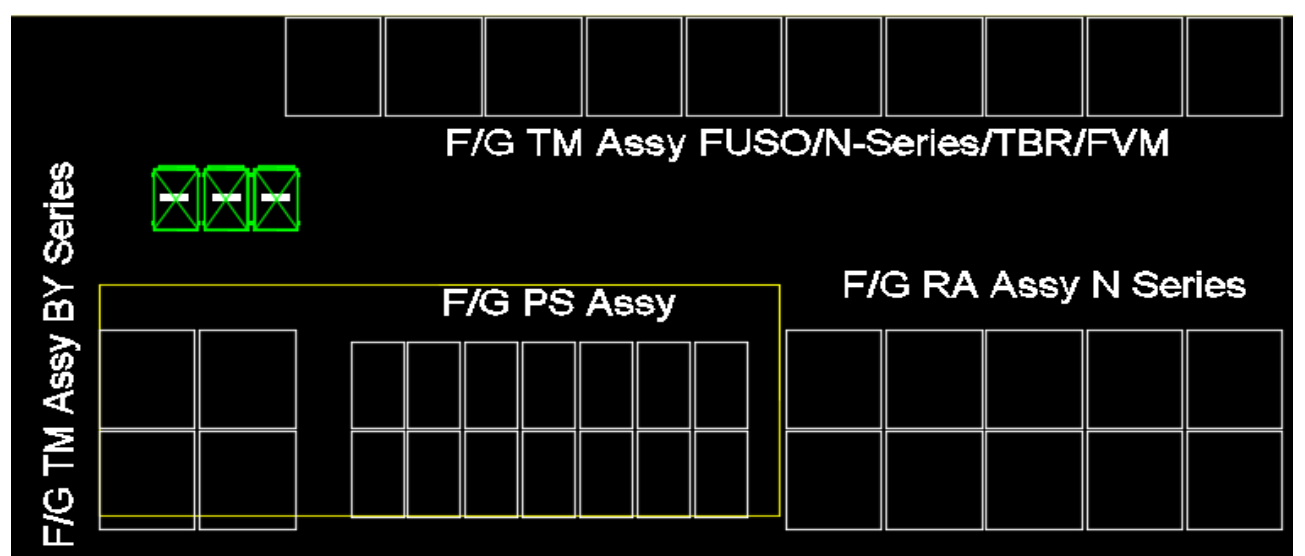

Gambar 4. Area pre deliveri check sebelumnya

Sumber: Hasil Pengolahan data Primer dan Sekunder tahun 2018

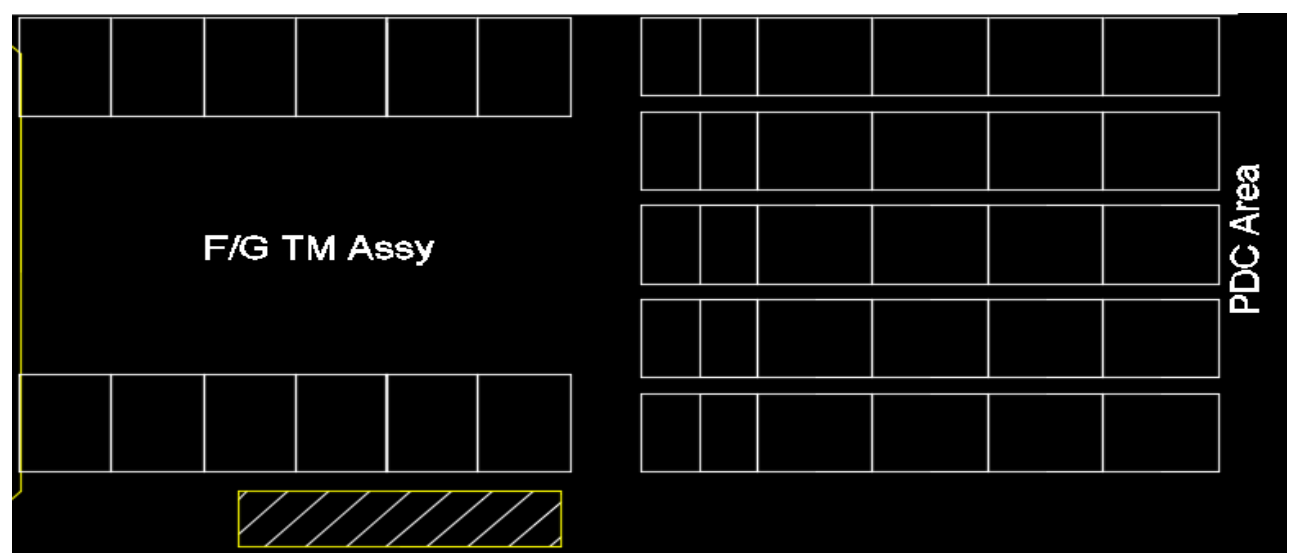

Gambar 5. Area pre delivery check sesudahnya

Sumber: Hasil Pengolahan data Primer dan Sekunder tahun 2018

\section{SIMPULAN}

Urutan kedatangan truk yang teratur dengan adanya sistem seperti diatas, menyebabkan tidak adanya keterlambatan pengiriman. Urutan pekerjaan petugas forklift yang sesuai dengan jam yang ditentukan pada TAG PDC membuat aliran delivery menjadi lancar tanpa adanya penumpukan pekerjaan. Pengaturan pola kedatangan truk dibuatkan standar yaitu dalam satu interval waktu tidak boleh ada lebih dari satu kedatangan truk.Pengaturan waktu yang tepat untuk mengatasi keterbatasan forklift yang ada adalah salah satu pilihan tepat, namun petugas forklift harus menyelesaikan pekerjaannya tepat waktu agar tidak mengalami penumpukan pekerjaan. Penggunaan tag PDC pada jalur PDC memudahkan petugas forklift mengetahui urutan pekerjaannya. Pengecekan terakhir dalam pengaturan pola kedatangan truk dengan menggunakan SOD akan terlihat apakah masih terdapat penumpukan kegiatan untuk forklift atau penumpukan antrian truk.

Diharapkan hasil penelitian ini dapat sebagai masukan bagi penelitian selanjutnya.

\section{DAFTAR PUSTAKA}

1. Chopra, S., \& Meidl, P. (2004)Supply Chain Management Strategy, Planning, and Operations, Second edition, Pearson education International

2. Heizer, J. \& render, B. (2005). Operation Management. $7^{\text {th }}$ edition. Pearson Education International

3. Hutapea, R. (2017). Analisis waktu proses bongkar muat barang dengan menggunakan teori antrian. JIEMS. Journal of Industrial Engineering \& Management Systems. Vol. 4 no.2.

4. Lam, J.S.L. \& Wong, H.N. (2018). Analysing business models of liner shipping companies. International Journal of Shipping and Transport Logistics.

5. Martono, R. (2015). Manajemen logistik terintegrasi. Tim PPM Manajemen Publishing. Jakarta 